\title{
Prospects of Wind-Diesel Generator-Battery Hybrid Power System: A Feasibility Study in Algeria
}

\author{
Djohra Saheb-Koussa, Mustapha Koussa, and Nourredine Said
}

Centre de Développement des Energies Renouvelables (CDER), 16340 Algeries, Algeria

Correspondence should be addressed to Djohra Saheb-Koussa; dkoussa@cder.dz

Received 11 March 2013; Revised 18 July 2013; Accepted 23 July 2013

Academic Editor: Oliver Probst

Copyright ( 2013 Djohra Saheb-Koussa et al. This is an open access article distributed under the Creative Commons Attribution License, which permits unrestricted use, distribution, and reproduction in any medium, provided the original work is properly cited.

The present work analyses the feasibility of a wind-diesel generator-battery hybrid system. The wind energy resource data are collected from the weather station at the Renewable Energy Development Center of Bouzareah in Algeria. The recorded values vary from $5.5 \mathrm{~m} / \mathrm{s}$ to $7 \mathrm{~m} / \mathrm{s}$ at $25 \mathrm{~m}$. The hybrid system analysis has shown that for a household consuming $1,270 \mathrm{kWh} / \mathrm{yr}$, the cost of energy is $1.205 \mathrm{USD} / \mathrm{kWh}$ and produces $2,493 \mathrm{kWh} / \mathrm{yr}$ in which $93 \%$ of electricity comes from wind energy. From this study, it is clear that the optimized hybrid system is more cost effective compared to the diesel generator system alone where the NPC and COE are equal, respectively, to 19,561 USD and $1.205 \mathrm{USD} / \mathrm{kWh}$ and 47,932 USD and $2.952 \mathrm{USD} / \mathrm{kWh}$. The sensitivity analysis predicts that the grid extension distance varies from 1.25 to $1.85 \mathrm{~km}$ depending on wind speed and fuel price which indicate a positive result to implement a stand-alone hybrid power system as an alternative to grid extension. In addition to the feasibility of this system, it can reduce the emission of the $\mathrm{CO}_{2}, \mathrm{SO}_{2}$, and $\mathrm{NO}_{x}$, respectively, from 4758 to 147 , from 9.45 to 0.294 , and from 105 to $3.23 \mathrm{~kg} / \mathrm{yr}$. Investments in autonomous renewable energy systems should be considered particularly in remote areas. They can be financed in the framework of the National Energy Action Plan of Algeria.

\section{Introduction}

An important challenge for Algeria to take up is the implementation of health care services in isolated coastal and mountainous regions of the north, high plains, and desert regions of the south.

Communities living there lack electricity for water sterilization, domestic use, medical services, education, and irrigation. These remote areas are not supplied with power lines. The important infant and maternal mortality rate in these regions is due essentially to transmissible diseases, scorpion poisoning, and malnutrition. The sub-Saharan localities are also threatened by the extension of sexually transmissible diseases as discussed by Armini [1]. The constructions of health clinics electrified by local resources such as solar and wind energy become the most suitable alternative.

In this context the aim of the present study is to control the feasibility, analyze, and simulate a wind-diesel generatorbattery hybrid system. Many research works including feasibility, optimization, and simulation studies have been carried out on hybrid energy systems [2-4]. Khelif et al. [2] have undertaken a feasibility of a hybrid PV/Battery/Diesel power plant using real meteorological data equipment costs to show the possibility of modifying a stand-alone diesel generator installation located in Afra, south of Algeria, into a hybrid system. Shafiullah et al. [3] have undertaken a feasibility study to investigate the solar and wind potential in some locations in Australia for renewable energy generation. Picohydro $(\mathrm{pH})$ and photovoltaic (PV) hybrid systems incorporating a biogas generator for remote villages in Cameroon have been simulated and presented by Nfah and Ngundam [4]. On the other hand, unlike the methods based on hourly, daily, and monthly average energy values, a statistical approach for the PV arrays size and the number of batteries of a standalone PV/wind hybrid system was presented by Bagul et al. [5]. They proposed a three-event probabilistic approach to overcome the limitations of the conventional two-event approach in matching the actual distribution of the energy generated by hybrid systems. Recently, Celik [6] has made a technoeconomic analysis and optimization of a PV/wind 
hybrid energy system. A comparative study with a standalone solar and wind system for the same conditions of load, insulation, and wind velocities has also been conducted. On a fundamentally different basis, Morgan et al. [7] have studied the performance of battery units in an autonomous hybrid energy system at various temperatures by considering the state of voltage (SOV) instead of the state of charge (SOC). Their algorithm enabled the prediction of the hybrid energy system performance at various battery temperatures. Yang et al. [8] have proposed an optimization technique following the loss of power supply probability (LPSP) model for a PV/wind hybrid system taking into account the system reliability. They demonstrated the utility of their model through a case study of a hybrid unit for a telecommunication system. Ashok [9] proposes a model based on different system components of a hybrid energy system and develops a general model to find an optimal combination of energy components for a typical rural community, minimizing the life cycle cost. Photovoltaic solar and wind energy conversion systems have been widely used for electricity supply in isolated locations far from the distribution network. If such systems are designed properly, they can provide a reliable service and operate in an unattended manner for extended periods of time. However, they suffer from the fluctuating characteristics of available solar and wind energy sources, which must be considered at design stage. The degree of desired reliability of a solar and wind process so as to meet a particular load can be fulfilled by a combination of properly sized wind turbine, PV panel, storage unit, and auxiliary energy as proposed in [10-12]. Saheb-Koussa et al. [13] have elaborated a technicoeconomic study of the hybrid system consisting of wind and photovoltaic with battery storage, in which the diesel generator is added to ensure continuous power supply and to take care of the intermittent nature of wind and photovoltaic. This serves as an additional tool that helps choosing the best system (wind or photovoltaic installation) when the two possibilities are technically possible. The choice was based on the determination of the option which corresponds to the least cost and to the best performances.

Bouzareah site is located at a latitude of 36.8 degrees north, a longitude of 3.04 degrees east, and a height of $345 \mathrm{~m}$ above the sea level. It is a mountainous site, where several houses are located face to the Mediterranean sea, at $2 \mathrm{~km}$ from the grid supply.

It has been then chosen for an application of renewable energy using wind power system. We have done a feasibility study which will be followed by an experimental investigation of the behavior of such system. The feasibility of using the wind-diesel-storage hybrid system was proven to be advantageous.

This project was financed by the national research project fund. However, the budget which has been allocated was not enough to include photovoltaic modules, which led us in this work to consider only the wind-diesel-storage system.

\section{Wind Resources Availability}

The availability of measured data is of considerable importance in the design of systems of energy production from

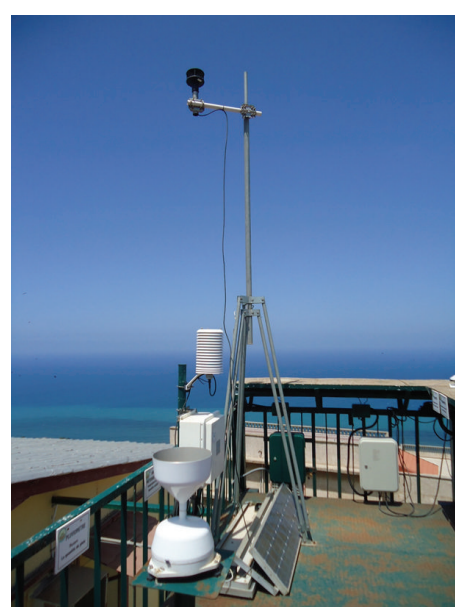

Figure 1: Meteorological station in the Center of Development of Renewable Energy.

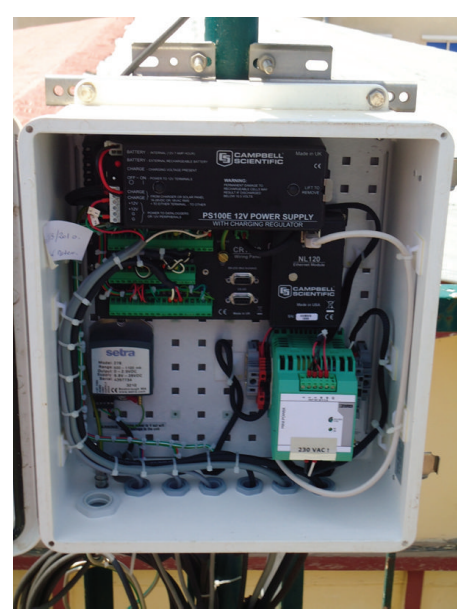

Figure 2: Data logger.

renewable resources. The use of measured data will allow researchers to improve accuracy and the efficiency of energy production in the local climate. Designers will be able to choose the optimal orientation, the best generator, products, and materials to be used.

Bouzareah station in Algiers is the main station where solar radiation and weather data are recorded for the last ten years.

The measured data are available in real time (updated every 5 minutes) and are made available through the website portal of Algerian Renewable Energy. The Center of Development of Renewable Energy offers through its website, a user interface to access and download freely the measured data for scientific and technical applications.

The actual station is a professional station which includes three pyranometers, a pyrheliometer, a sun tracker, several sensors for measuring temperature, humidity, rainfall, pressure, and duration of sunshine, an ultrasonic sensor for measuring the speed and direction of wind at $10 \mathrm{~m}$, and a data logger type CR1000 Campbell Scientific (see Figures 1, 2, and 3). 

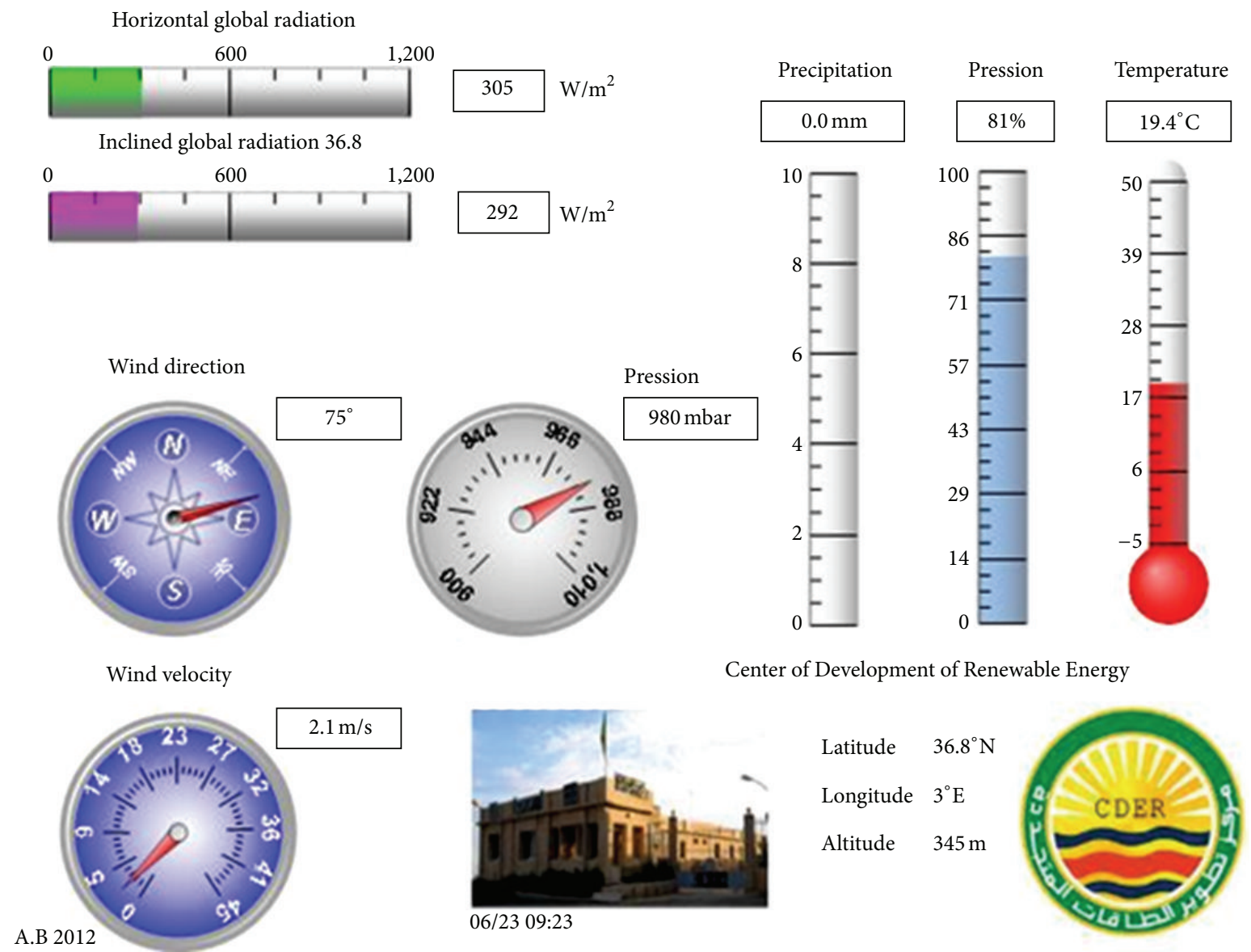

FIGURE 3: Real-time measured data.

\section{Site Characteristics}

The Bouzareah site is a coastal site, and according to the Köppen-Geiger climate classification [14] it can be considered as a temperate climate with a hot and arid summer (CSA climate). Using data measurement, recorded during the last five years, the monthly mean daily wind speed is calculated at $25 \mathrm{~m}$. Figure 4 shows the corresponding yearly evolution as well as the measured one at $10 \mathrm{~m}$ [15]. Thus, it is observed that the more probable wind speeds are in the range of $3.5 \mathrm{~m} / \mathrm{s}-$ $5.5 \mathrm{~m} / \mathrm{s}$ at $10 \mathrm{~m}$ and in the range of $5.5 \mathrm{~m} / \mathrm{s}-7 \mathrm{~m} / \mathrm{s}$ at $25 \mathrm{~m}$, being less probable when the speed increases.

The distribution of wind speed's probabilities at Bouzareah is obtained applying the mathematical expression of Weibull's function [16], and it is defined by the following formula:

$$
f(v)=\left(\frac{k}{c}\right)\left(\frac{v}{c}\right)^{k-1} \exp \left[\left(\frac{v}{c}\right)^{k}\right],
$$

where $k$ is the shape parameter, describing the dispersion of the data, and $c$ is the scale parameter, with units of speed $(\mathrm{m} / \mathrm{s})$. The two parameters $c$ and $k$ are related to the average wind speed by the following relation:

$$
\bar{v}=c \Gamma\left(\frac{1}{k}+1\right)
$$

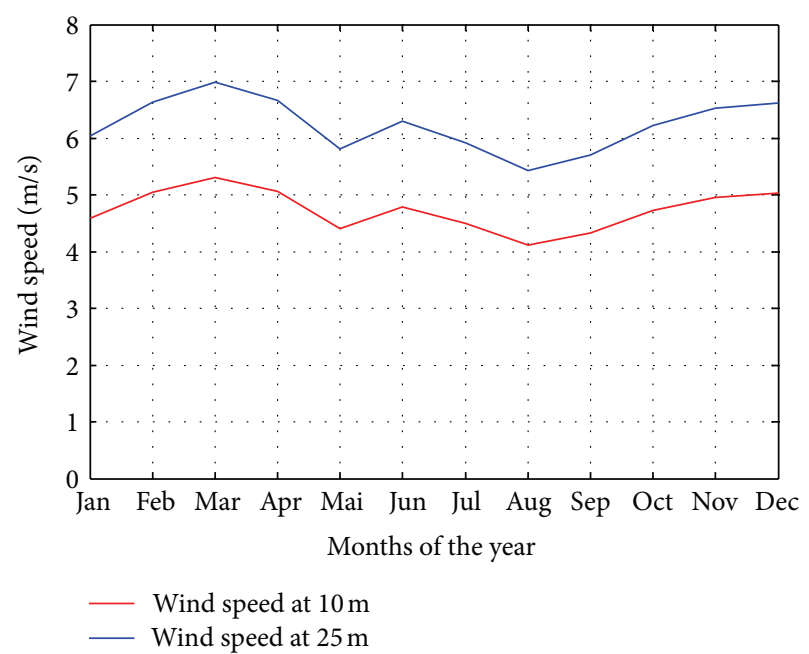

FIgURE 4: Monthly wind speed at Bouzareah at $10 \mathrm{~m}$ and $25 \mathrm{~m}$ height.

where $\Gamma$ is the gamma function. To fit a Weibull distribution of measured wind data, HOMER uses the maximum likelihood method discussed by Stevens and Smulders [17]. The site characteristics are shown in Table 1, and the predicted and 
TABLE 1: Site description: Bouzareah; position: $3,04^{\circ} \mathrm{N} 36,8^{\circ} \mathrm{E}$; anemometer height: $10 \mathrm{~m}$.

\begin{tabular}{lcccc}
\hline - & Unit & Measured & Weibullfit & Discrepancy \\
\hline Mean wind speed & $\mathrm{m} / \mathrm{s}$ & 3,49 & 3,47 & $0,70 \%$ \\
Mean power density & $\mathrm{W} / \mathrm{m}^{2}$ & 51,42 & 51,88 & $0,89 \%$ \\
\hline
\end{tabular}

actual wind rose and speed probability functions are shown in Figure 5.

\section{Description of the Retained System}

The power plant under investigation (Figure 6) consists of 01 diesel generator of $1 \mathrm{~kW}$, one wind generator Whisper 200 , batteries of $12 \mathrm{~V}$ with a nominal capacity of $100 \mathrm{Ah}$, a converter (DC/AC), and a load. This device can be extended to isolated coastal and mountainous regions of the north, high plains, and desert regions of Algeria. In hybrid mode, the diesel generator will be in operation only a few hours during the year for supplying the load with electricity and recharging the battery. This operation mode allows the reduction fuel consumption because of the fact that operation in base load is ensured by the wind generator.

\section{Electric Loads}

In this study, we consider a home consuming an energy load of $3.5 \mathrm{kWh}$ /day with a $0.74 \mathrm{~kW}$ peak demand. Figure 7 shows the daily load profile graph. In this analysis, it is considered the use of fluorescent lights/compact fluorescent lights/ energy saving bulbs in place of incandescent lamps which results drastic load reduction.

\section{Hybrid System Components}

6.1. Wind Turbine. The load demand is very low, and the price per $\mathrm{kW}$ turbine cost is very high for low capacities wind turbine compared to that of high capacity ones. Also low capacity wind turbine is not much available. Nowadays, research and development are going on to improve the technology and design low capacity turbines with low cutin speed around $2.5 \mathrm{~m} / \mathrm{s}$. So, for the Bouzareah site which presents a medium wind potential, turbine from southwest wind power (model Whisper 200; capacity $1 \mathrm{~kW}$; lifetime 20 years) has been considered at the cost of 10000 USD with tower and installation, replacement and O\&M costs are, respectively, equal to $\$ 8000$ and $\$ 80$. This is a three-blade model with a diameter of $2.7 \mathrm{~m}$ and a hub height of $25 \mathrm{~m}$. Moreover, Figure 8 shows the power and Cp curves provided by the manufacturer.

6.2. Diesel Generator. Diesel generator supplies a significant amount of energy of the studied load. The selected diesel generator is characterized by an operating life time of 15000 hours, with power generating of $0.2 \mathrm{~kW}$ to $5 \mathrm{~kW}$, by fuel consumption of 0.25 liters per hour, and with $30 \%$ of minimum load ratio. The generator has been considered at the cost of 1500 USD, replacement cost is $\$ 1200$, and O\&M cost is $\$ 0.05$. The selected diesel generator has a 15000 lifetime operating hours.

6.3. Battery with Controller. As the system considered the AC load only, battery and controller were also considered as a main part of the system. Battery from vision battery company (Model Vision 6FM200D; nominal voltage: $12 \mathrm{~V}$; nominal capacity: $100 \mathrm{Ah}$; lifetime throughput $917 \mathrm{Ah}$ ) has been used at a cost of $\$ 253$, with controller charge, replacement cost is $\$ 200$, and O\&M cost is $\$ 1$.

6.4. Converter. A converter is required for systems in which DC components serve an AC load or vice versa. A converter can be inverter (DC to AC) or rectifier (AC to DC) or both. The selected converter has a 15 year lifetime and efficiency equal to $90 \%$ for the inverter and $85 \%$ for the rectifier. The installation cost for a $1.0 \mathrm{~kW}$ size converter is $\$ 2040$, replacement cost is $\$ 2000$, and O\&M cost is considered $\$ 2$.

6.5. Economics and Constraints. The project lifetime has been considered to be 25 years, and the annual interest rate has been taken $10 \%$. The operation and maintenance cost has been taken $300 \$ / y e a r$. There is no capacity shortage for the system, and operating reserve is $10 \%$ of hourly load.

\section{Results}

Models were developed for the selected location in Algeria using HOMER simulation tools (Figure 9). The HOMER software developed by the National Renewable Energy Laboratory (NREL), USA, helps to design off-grid and gridconnected systems; it provides a method for finding the least cost system on the basis of a given load size, system components, and data for energy sources.

There are many possible system configurations that are possible alternatives to grid extension. HOMER performs the energy balance calculations for each system configuration and determines whether a configuration is feasible. The system cost calculations account for costs such as capital, replacement, operation and maintenance, and interest. HOMER displays the entire possible system configuration, sorted by net present cost (NPC).

7.1. Optimization Results. The optimization results show that the optimal wind-diesel generator-battery hybrid has lowest NPC (19,561 USD) with COE 1.205 USD/kWh; see Table 2. From Table 2 it is shown that the optimized wind-diesel generator-battery reduces the NPC of about $2 \%, 54 \%$, and $59 \%$ compared with wind-diesel generator-battery, winddiesel generator, and diesel generator only, respectively, which has a similar effect on the cost of energy (COE), diesel generator hours of operation, and a quantity of fuel consumption.

The annual electricity production from the optimal design solution is $2.493 \mathrm{~kW} / \mathrm{yr}$ in which $93 \%$ electricity comes from a wind source and 7\% electricity comes from a diesel generator with an annual capacity of shortage $0 \%$, this is depicted in Figure 10. The proposed hybrid system always 

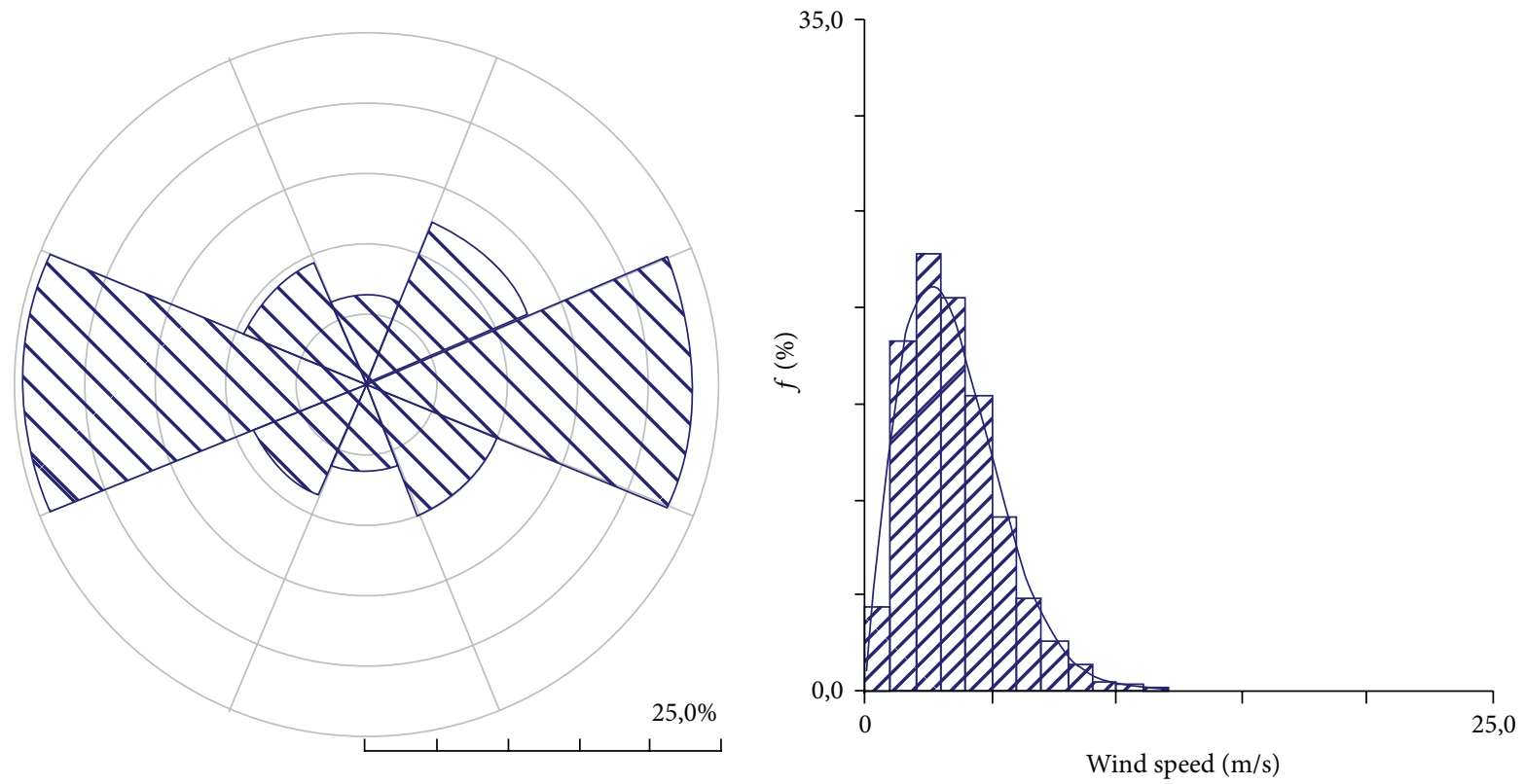

FIGURE 5: Wind rose and speed probability density function.

TABLE 2: Optimization results.

\begin{tabular}{|c|c|c|c|c|c|c|c|c|c|c|c|}
\hline Options & $\begin{array}{c}\mathrm{Gr} \\
\mathrm{kW}\end{array}$ & $\begin{array}{c}\text { Whisper } \\
200\end{array}$ & Battery & $\begin{array}{c}\text { Converter } \\
\mathrm{kW}\end{array}$ & $\begin{array}{c}\text { Initial } \\
\text { cost }(\$)\end{array}$ & $\begin{array}{c}\text { Operating } \\
\text { cost }(\$)\end{array}$ & $\begin{array}{c}\text { Total } \\
\text { NPC (\$) }\end{array}$ & $\begin{array}{c}\mathrm{COE} \\
\$ / \mathrm{kWh}\end{array}$ & $\begin{array}{c}\text { Renewable } \\
\text { fraction (\%) }\end{array}$ & $\begin{array}{c}\text { Diesel } \\
(1 / y r)\end{array}$ & $\begin{array}{c}\mathrm{Gr} \\
(\mathrm{h} / \mathrm{yr})\end{array}$ \\
\hline W-Gr-B & 1.3 & 1 & 6 & 1.3 & 14,318 & 410 & 19,561 & 1.205 & 93 & 56 & 131 \\
\hline Gr-B & 1.3 & & 3 & 1.3 & 5,277 & 1,147 & 19,944 & 1.228 & 0 & 590 & 1,376 \\
\hline W-Gr & 1.3 & 1 & & 1.3 & 13,193 & 2,309 & 42,706 & 2.63 & 0.53 & 1,053 & 5,134 \\
\hline Gr & 1.3 & & & & 1,950 & 3,597 & 47,932 & 2.952 & 0 & 1,803 & 8,759 \\
\hline
\end{tabular}

Gr: diesel generator; B: battery; W: wind.

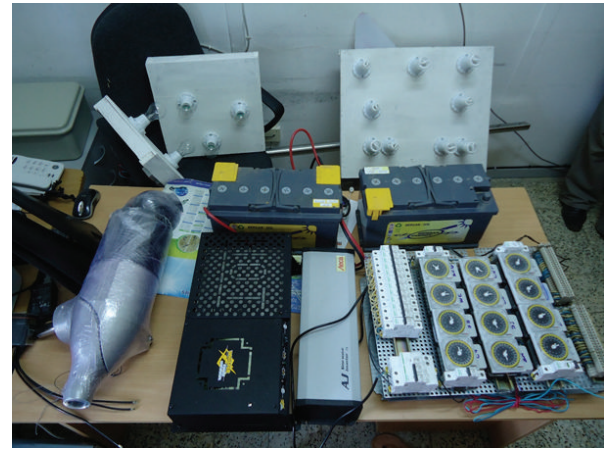

FIGURE 6: Components of the retained system.

produces more energy than the load demand for a few moments which is called excess energy. Thus, the excess energy is the surplus electrical energy that must be useless since it is unable to serve a load or charge the battery bank. The excess energy that must be useless because it is powerless to serve a load or charge the battery bank. The excess energy produced by the hybrid system is $36.2 \%$ and is associated with COE. For the reason that COE is defined as the ratio

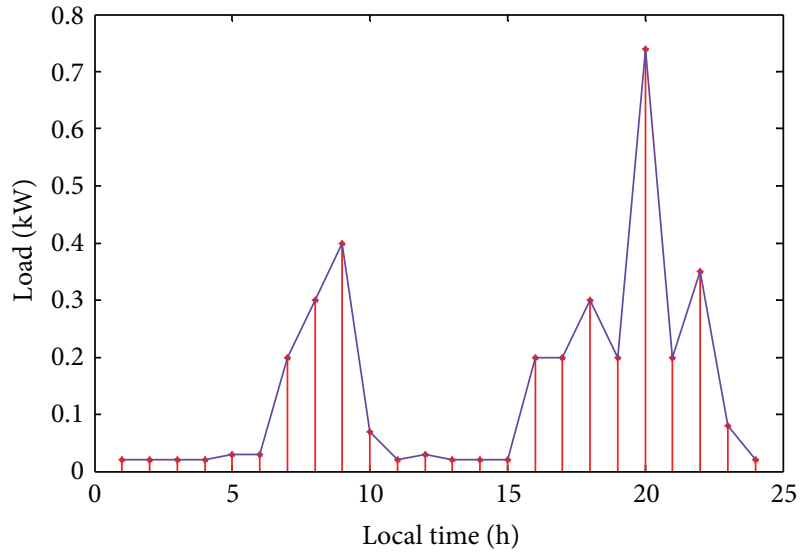

FIGURE 7: Daily load demand of proposed site.

of the total annualized cost and annual load served, reducing the annualized excess energy and increasing the annual load served can optimize the cost of energy. On the other hand, the optimized configuration has $0 \%$ unmet load which is electrical load that the optimized system is unable to serve. 


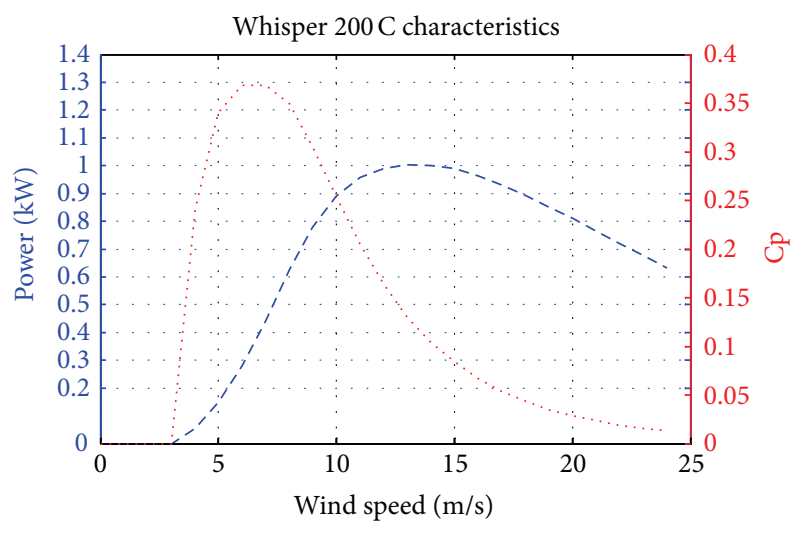

FIGURE 8: The Whisper 200 wind turbine characteristics.

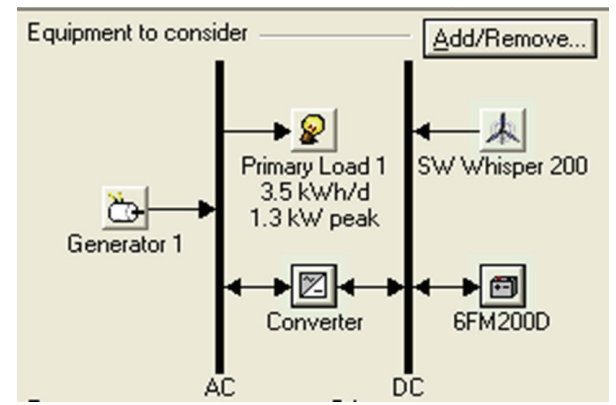

FIGURE 9: Configuration of the proposed wind-diesel-battery hybrid system.

7.2. Comparison with Grid. In the present evaluation the distance of the proposed site (Bouzareah) is not identified; however, the breakeven, grid extensions distance can be determined. The breakeven grid extension distance is the distance from the grid which makes the net present cost of extending the grid equal to the net present cost of the standalone system. Farther away from the grid, the stand-alone system is optimal. Nearer to the grid, grid extension is optimal. Figure 11 compares the costs of these two possibilities and shows that the breakeven grid extension is $1.8 \mathrm{~km}$. The slope of the grid extension curve represents the NPC of grid extension in 20,000 USD $/ \mathrm{km}$.

7.3. Sensitivity Results. From sensitivity analysis, the models were analyzed to explore their characteristics using optimal system type and line graph options and spider graph. Figure 12 represents the sensitivity results from the data collected from Bouzareah. It can be seen that, with the increase of wind speed, the Total Net Present Cost and levelized Cost of Energy reduce significantly. From these graphical representations, it has concluded that a particular system would be optimal at a certain sensitivity of variables or conditions.

Figure 13 shows the sensitivity results for the optimum system type from which it can be seen that a power system only fed by diesel generator- (Gr-) battery is only cost competitive when the wind conditions are below $3.5 \mathrm{~m} / \mathrm{s}$. These

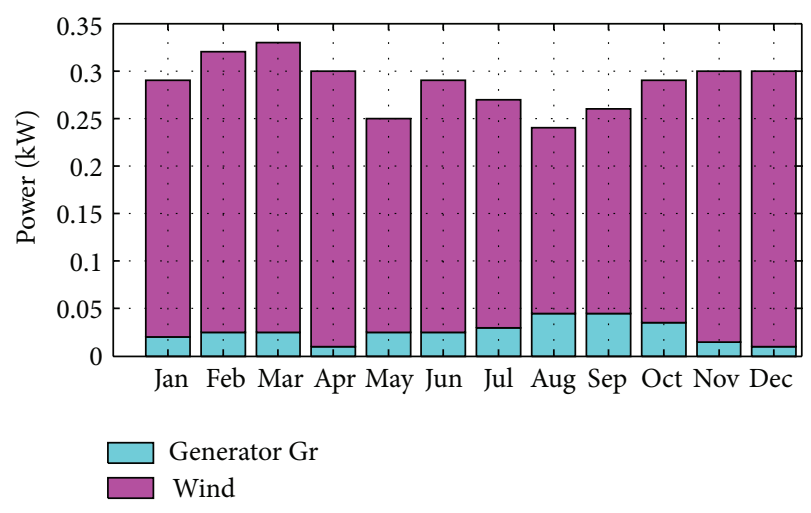

FIGURE 10: Monthly average electric production from the optimized wind-diesel-battery hybrid system.

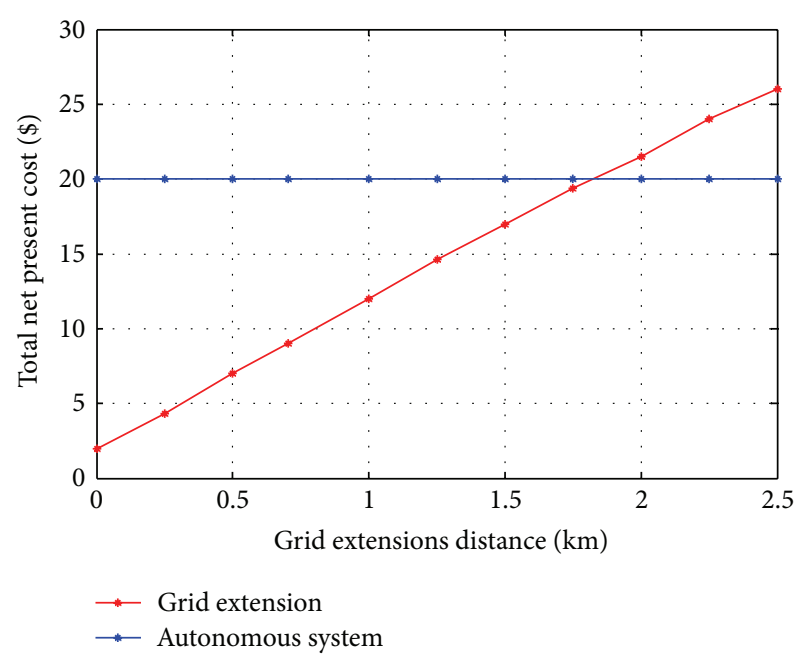

FIGURE 11: The breakeven grid extension distance.

values are in accordance with the ones given by manufacturers and project developers around the world about the minimum natural conditions for their technologies to be feasible. In the case of small wind energy, the explanation is that the cut-in speed is normally around $3.5 \mathrm{~m} / \mathrm{s}$. This is a minimum value for specific wind speed at specific times (wind must blow at a minimum speed of $3.5 \mathrm{~m} / \mathrm{s}$ for the turbine to produce electricity). Therefore, a wind-diesel generator-battery system is suitable when the wind speed and diesel price are above, respectively, $3.5 \mathrm{~m} / \mathrm{s}$ and $2.1 \$ / \mathrm{L}$, and a wind-battery system is suitable when the wind speed and diesel price are above, respectively, $6 \mathrm{~m} / \mathrm{s}$ and $0.7 \$ / \mathrm{L}$.

The effect of sensitive variables on grid extension distance is shown in Figure 14. The breakeven grid extension distance varies from 1.25 to $1.85 \mathrm{~km}$. The sensitivity analysis indicates that the breakeven grid extension distance reduces and grows up with the increasing, respectively, of wind speed and fuel price.

7.4. Pollutants Emission. The use of renewable energy sources in the generation of energy reduces the emission of $\mathrm{CO}_{2}$, 


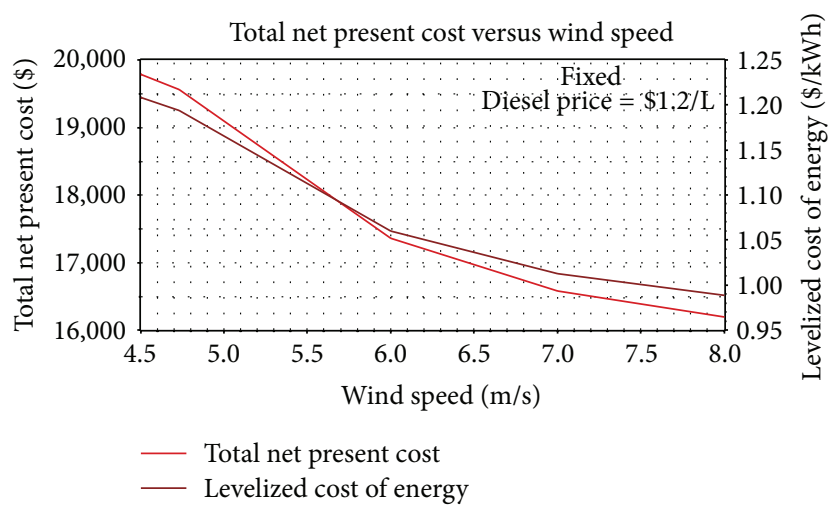

FIgURE 12: Sensitivity results for Bouzareah.

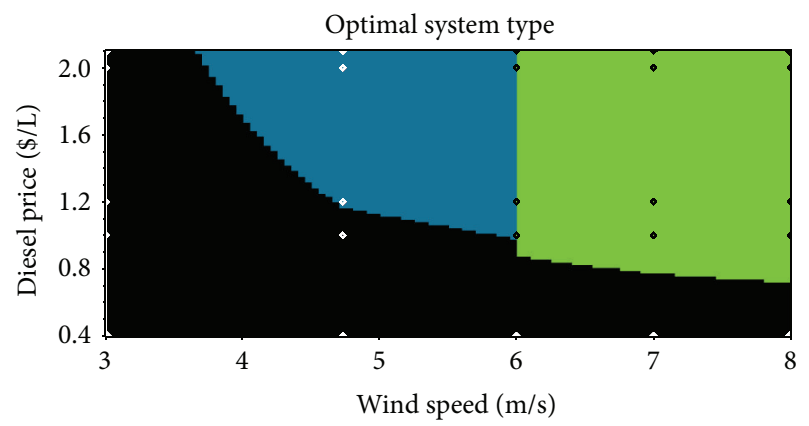

System types

- Gr/battery

$\square$ Wind/battery

口 Wind/Gr/battery

FIGURE 13: Sensitivity results for the optimal system type.

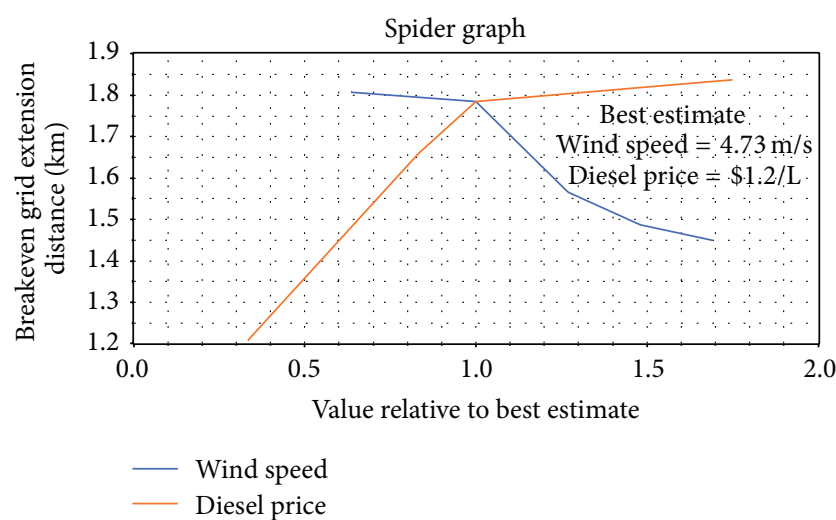

FIGURE 14: Variation of breakeven grid extension distance with wind speed and diesel price.

$\mathrm{SO}_{2}$, and $\mathrm{NO}_{x}$ in the atmosphere that helps to fight global warming. This study estimates the total yearly emissions from wind-diesel generator-battery, diesel generator-battery, wind-diesel generator, and diesel generator only. In this way, Figures 15, 16, and 17 represent, respectively, the yearly emissions of $\mathrm{CO}_{2}, \mathrm{SO}_{2}$, and $\mathrm{NO}_{x}$ for the developed model at the selected location in Algeria. For Bouzareah, the standard

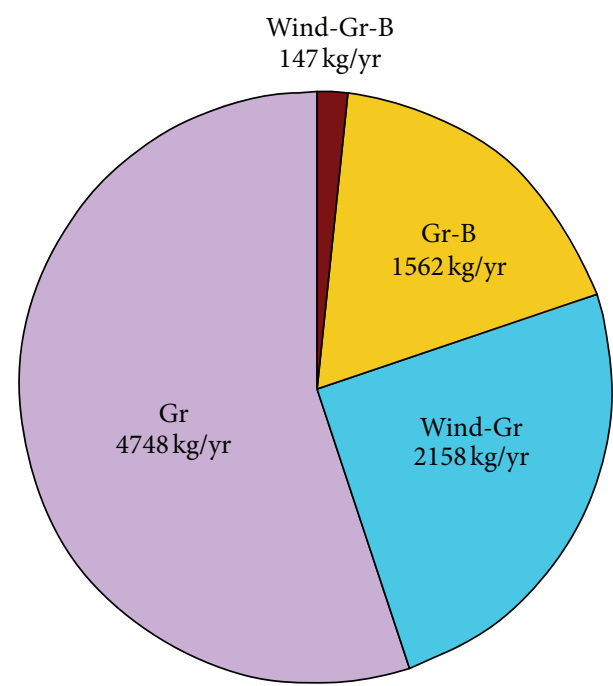

Figure 15: Annual emissions (kg/yr) of carbon dioxide $\left(\mathrm{CO}_{2}\right)$ of each type of system.

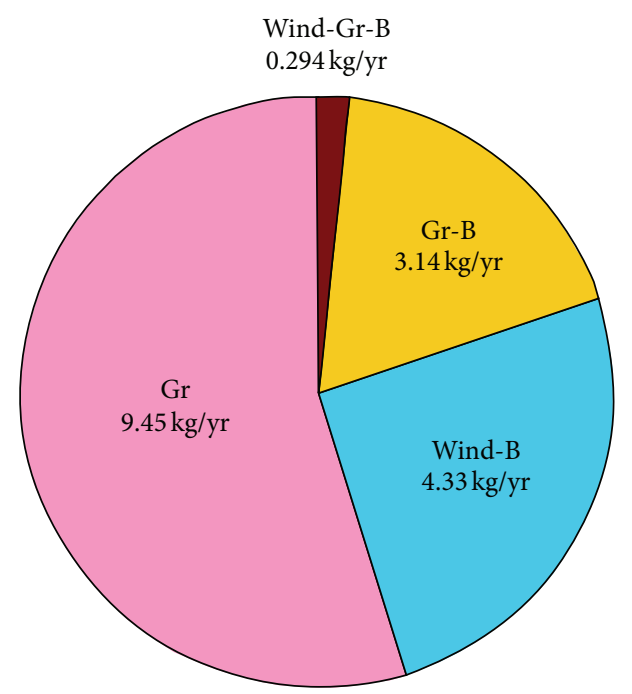

Figure 16: Annual emissions (kg/yr) of sulfur dioxide $\left(\mathrm{SO}_{2}\right)$ of each type of system.

diesel generator only system emitted $4758 \mathrm{~kg} \mathrm{CO}$ per year, $9.45 \mathrm{~kg} \mathrm{SO}_{2}$ per year, and $105 \mathrm{~kg} \mathrm{NO}_{x}$ per year, while a winddiesel generator-battery system emitted only $147 \mathrm{~kg} \mathrm{CO}_{2}$ per year, $0.294 \mathrm{~kg} \mathrm{SO}_{2}$ per year, and $3.23 \mathrm{~kg}$ per year.

\section{Conclusion}

This study simulates and analysis a wind-diesel generatorbattery hybrid system using HOMER software. The wind energy resource data are collected from the weather station of the Renewable Energy Development Center of Bouzareah in Algeria. So, from this study it is clear that the optimized wind-diesel generator-battery hybrid system is more cost effective compared to diesel generator alone system where the NPC and COE are equal, respectively, to 19,561 USD and 


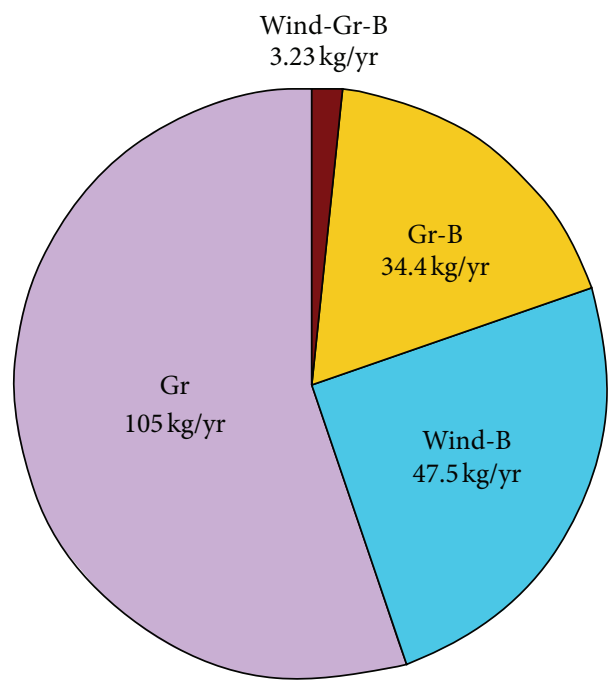

Figure 17: Annual emissions $(\mathrm{kg} / \mathrm{yr})$ of nitrogen oxide $\left(\mathrm{NO}_{x}\right)$ of each type of system.

1.205 USD/kWh and 47,932 USD and 2.952 USD/kWh. From the sensitivity analysis, we predict that the grid extension distance varies from 1.25 to $1.85 \mathrm{~km}$ depending on wind speed and fuel price which indicate a positive result to implement a stand-alone hybrid power system as an alternative to grid extension. In addition to the feasibility of this system, it can reduce the emission of the $\mathrm{CO}_{2}, \mathrm{SO}_{2}$, and $\mathrm{NO}_{x}$, respectively, from 4758 to 147 , from 9.45 to 0.294 , and from 105 to $3.23 \mathrm{~kg}$ per year.

This study is still in its preliminary phase, and further investigations are needed such as

(i) making an experimental investigation of real system performances by using all components presented in Section 3;

(ii) the system cost could be reduced by combining a wind system with other energy sources such as photovoltaic;

(iii) finally, it is concluded that the obtained results from this study could be used in Algerian's National Energy Action Plan for the provision of small electrical energy load scale services in the key sectors involved in remote areas.

\section{Conflict of Interests}

None of the authors of this paper has a financial or personal relationship with other people or organisations that could inappropriately influence or bias the content of the paper.

\section{References}

[1] M. Armini, "Renewable energy system for rural health clinic in Algeria : HOMER application," Renewable Energy Research Centre Algeria, 2009, http://homerenergy.com/webcast-downloads/Malika_Amini/health.pdf.
[2] A. Khelif, A. Talha, M. Belhamel, and A. H. Arab, "Feasibility study of hybrid Diesel-PV power plants in the southern of Algeria: case study on AFRA power plant," International Journal of Electrical Power \& Energy Systems, vol. 43, no. 1, pp. 546-553, 2012.

[3] G. M. Shafiullah, M. T. O. Amanullah, A. B. M. Shawkat Ali, D. Jarvis, and P. Wolfs, "Prospects of renewable energy-a feasibility study in the Australian context," Renewable Energy, vol. 39, no. 1, pp. 183-197, 2012.

[4] E. M. Nfah and J. M. Ngundam, "Feasibility of pico-hydro and photovoltaic hybrid power systems for remote villages in Cameroon," Renewable Energy, vol. 34, no. 6, pp. 1445-1450, 2009.

[5] A. D. Bagul, Z. M. Salameh, and B. Borowy, "Sizing procedure a stand-alone hybrid wind-photovoltaic system using a threeevent probability density approximation," Solar Energy, vol. 56, no. 4, pp. 323-335, 1996.

[6] A. N. Celik, "Optimisation and techno-economic analysis of autonomous photovoltaic-wind hybrid energy systems in comparison to single photovoltaic and wind systems," Energy Conversion and Management, vol. 43, no. 18, pp. 2453-2468, 2002.

[7] T. R. Morgan, R. H. Marshall, and B. J. Brinkworth, “'ARES’-a refined simulation program for the sizing and optimisation of autonomous hybrid energy systems," Solar Energy, vol. 59, no. 4-6, pp. 205-215, 1997.

[8] H. X. Yang, L. Lu, and J. Burnett, "Weather data and probability analysis of hybrid photovoltaic-wind power generation systems in Hong Kong," Renewable Energy, vol. 28, no. 11, pp. 1813-1824, 2003.

[9] S. Ashok, "Optimised model for community-based hybrid energy system," Renewable Energy, vol. 32, no. 7, pp. 1155-1164, 2007.

[10] G. C. Bakos and N. F. Tsagas, "Technoeconomic assessment of a hybrid solar/wind installation for electrical energy saving," Energy and Buildings, vol. 35, no. 2, pp. 139-145, 2003.

[11] H. Yang, L. Lu, and W. Zhou, "A novel optimization sizing model for hybrid solar-wind power generation system," Solar Energy, vol. 81, no. 1, pp. 76-84, 2007.

[12] H. Lund, "Large-scale integration of optimal combinations of $\mathrm{PV}$, wind and wave power into the electricity supply," Renewable Energy, vol. 31, no. 4, pp. 503-515, 2006.

[13] D. Saheb-Koussa, M. Haddadi, and M. Belhamel, "Economic and technical study of a hybrid system (wind-photovoltaicdiesel) for rural electrification in Algeria," Applied Energy, vol. 86, no. 7-8, pp. 1024-1030, 2009.

[14] M. C. Peel, B. L. Finlayson, and T. A. McMahon, "Updated world map of the Köppen-Geiger climate classification," Hydrology and Earth System Sciences, vol. 11, no. 5, pp. 1633-1644, 2007.

[15] HOMER, "Getting started guide for HOMER version 2.1.2005," National Renewable Energy Laboratory, Operated for the U.S. Department of Energy Office of Energy Efficiency and Renewable Energy, 2009.

[16] W. Weibull, "A statistical distribution of wide applicability," Journal of Applied Mechanics, vol. 18, pp. 293-297, 1957.

[17] M. J. M. Stevens and P. T. Smulders, "The estimation of the parameters of the Weibull wind speeds distribution for wind speed utilization purposes," Wind Engineering, vol. 3, no. 2, pp. $132-145,1979$. 


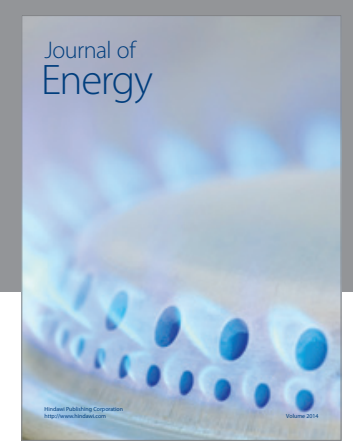

Journal of

Industrial Engineering
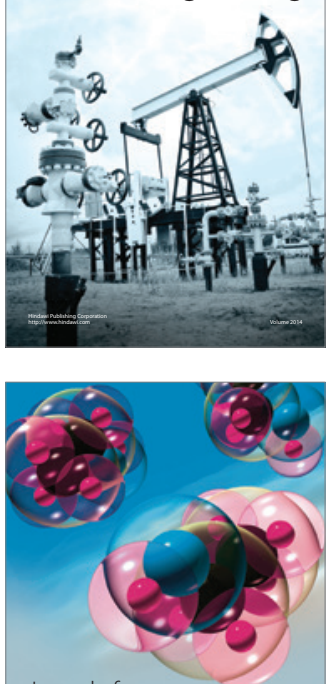

Fuels
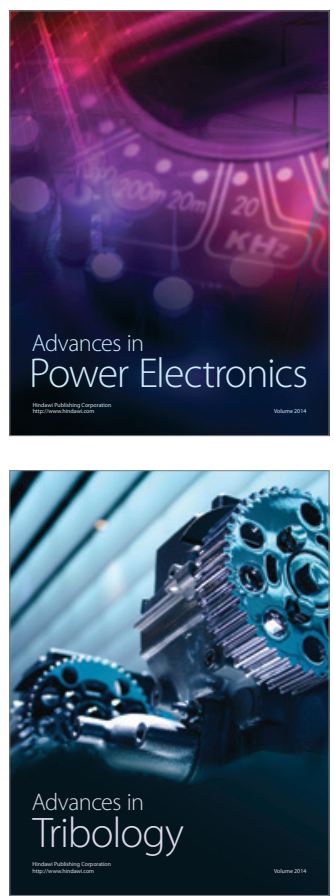

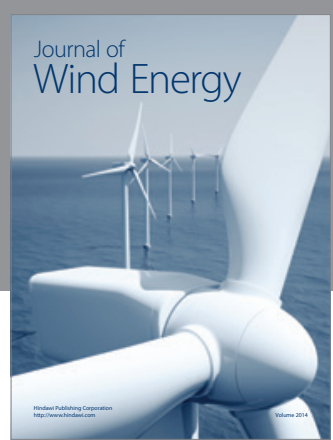

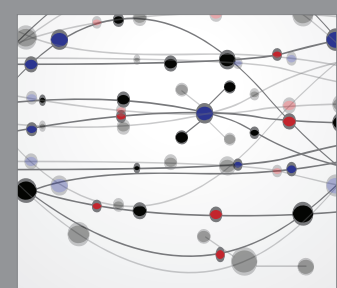

The Scientific World Journal

Submit your manuscripts at http://www.hindawi.com

Journal of

Structures
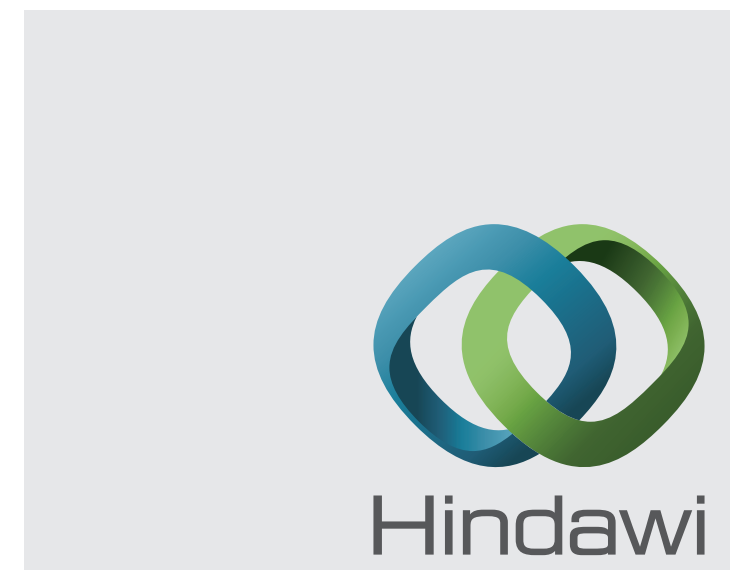

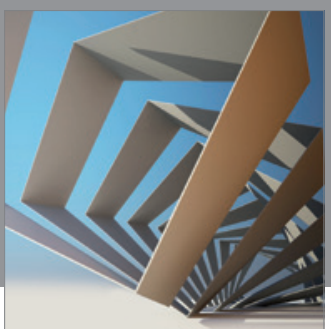

Rotating

Machinery
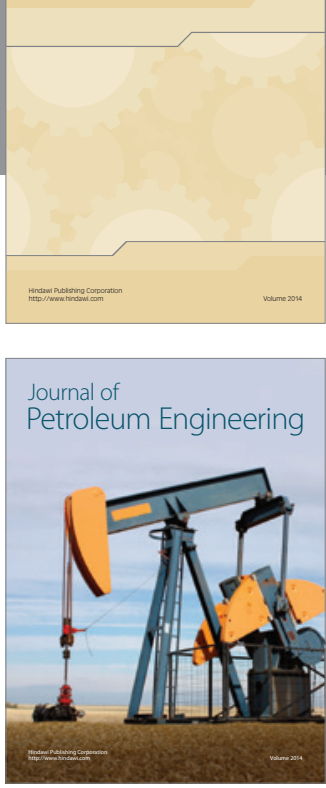

Journal of

Solar Energy
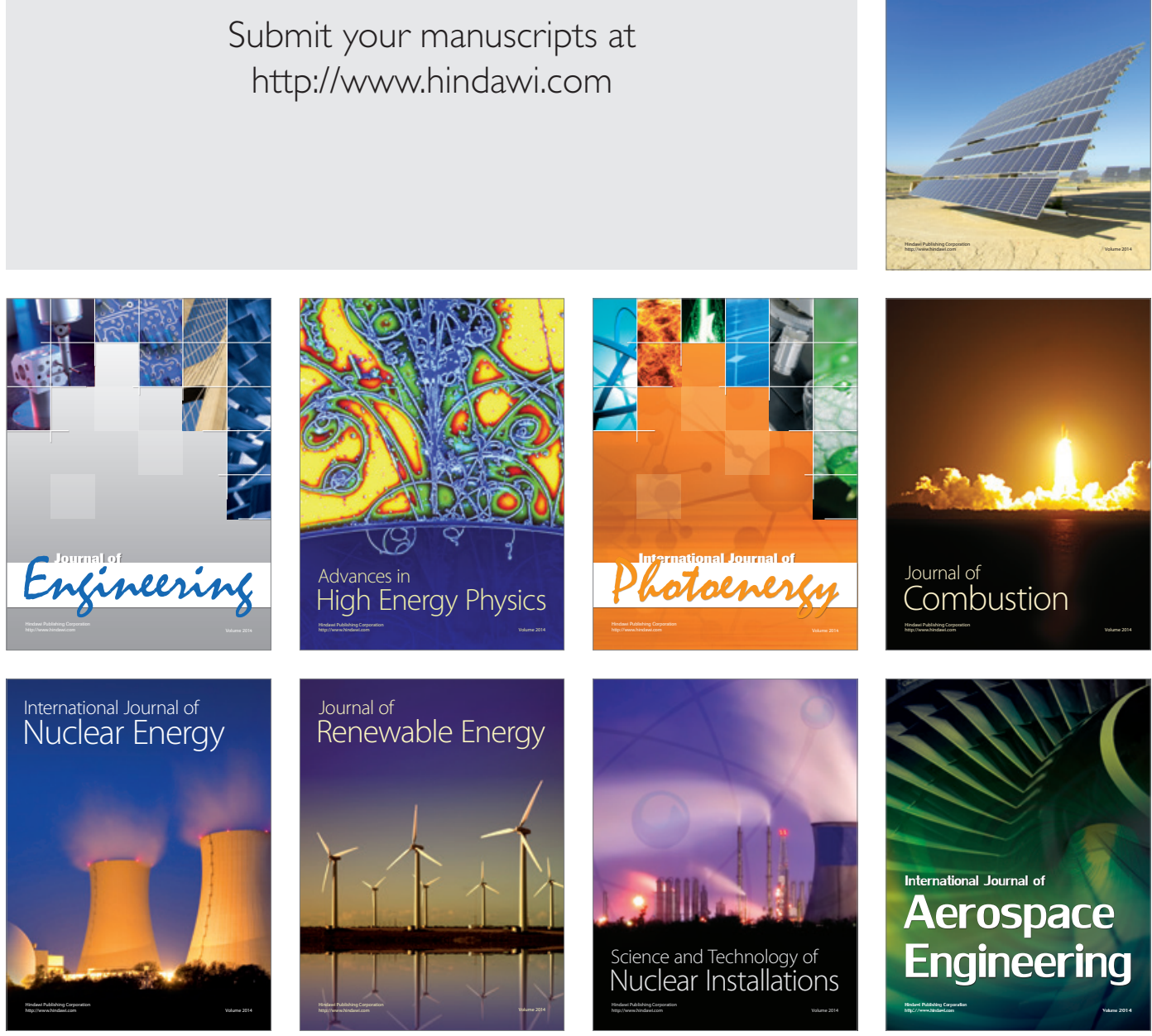